\title{
Cardiovascular diseases and vulnerable plaques: data, modeling, predictions and clinical applications
}

\author{
Dalin Tang ${ }^{1,2^{*}}$, Zhi-Yong Li', Frank Gijsen ${ }^{3}$, Don P Giddens ${ }^{4}$
}

* Correspondence: dtang@wpi.edu
'School of Biological Science and
Medical Engineering, Southeast
University, Nanjing 210096, China

\section{Introduction: two symposia on "cardiovascular diseases and vulnerable plaques"}

Cardiovascular disease (CVD) is the leading cause of death worldwide. Huge effort has been made in many disciplines including medical imaging, computational modeling, biomechanics, bioengineering, medical devices, animal and clinical studies, population studies as well as genomic, molecular, cellular and organ-level studies seeking improved methods for early detection, diagnosis, prevention and treatment of these diseases [1-14]. However, the mechanisms governing the initiation, progression and the occurrence of final acute clinical CVD events are still poorly understood. A large number of victims of these diseases who are apparently healthy die suddenly without prior symptoms. Available screening and diagnostic methods are insufficient to identify the victims before the event occurs $[8,9]$. Most cardiovascular diseases are associated with vulnerable plaques. A grand challenge here is to develop new imaging techniques, predictive methods and patient screening tools to identify vulnerable plaques and patients who are more vulnerable to plaque rupture and associated clinical events such as stroke and heart attack, and recommend proper treatment plans to prevent those clinical events from happening.

Articles in this special issue came from two symposia held recently focusing on "Cardiovascular Diseases and Vulnerable Plaques: Data, Modeling, Predictions and Clinical Applications." One was held at Worcester Polytechnic Institute (WPI), Worcester, MA, USA, July 13-14, 2014, right after the $7^{\text {th }}$ World Congress of Biomechanics. This symposium was endorsed by the World Council of Biomechanics, and partially supported by a grant from NIH-National Institute of Biomedical Image and Bioengineering. The other was held at Southeast University (SEU), Nanjing, China, April 18-20, 2014.

\section{Invited speakers, presenters, and participants}

The objective of the two symposia was to invite experts and researchers world-wide in the cardiovascular diseases and vulnerable plaque research area to exchange the most updated research techniques and findings, to provide training to newer researchers and students, and form a joined force to push the image-based research effort closer to clinical applications. Invited speakers and participants at the WPI symposium included Don Giddens and David Molony (Georgia Tech), Jonathon Gillard and Zhongzhao Teng (Cambridge University, UK), Peter Stone (Harvard Medical School), David Saloner (UCSF), Jolanda Wentzel and Frank Gijsen (Erasmus Medical Center, the

C 2015 Tang et al: licensee BioMed Central Ltd. This is an Open Access article distributed under the terms of the Creative Commons Attribution License (http://creativecommons.org/licenses/by/4.0), which permits unrestricted use, distribution, and reproduction in any medium, provided the original work is properly cited. The Creative Commons Public Domain Dedication waiver (http:// creativecommons.org/publicdomain/zero/1.0/) applies to the data made available in this article, unless otherwise stated. 
Netherlands), Natalia Maldonado from Sheldon Weinbaum's group (CUNY), Rupak Banerjee and Namheon Lee (University of Cincinnati), Kristen Billiar, Glenn Gaudette, Mayer Humi, Roger Lui, Marcus Sarkis, and Zheyang Wu (WPI), Umberto Morbiducci and Diego Gallo (Politecnico di Torino, Italy), Michael Walsh, Hilary E. Barrett and Cunnane Eoghan (University of Limerick, Limerick, Ireland), Shunichi Kobayashi (Shinshu Univ, Japan), Haichao Han (University of Texas at San Antonio), Susan Lessner (University of South Carolina School of Medicine), Takeo Matsumoto and Shukei Sugita (Nagoya Institute of Technology, Japan), Katherine Zhang (Boston University), Liang Wang and Heng Zuo (WPI), and many others. Abstracts presented at the WPI symposium provided here for easy reference [32-49].

Invited international and domestic speakers and participants at the SEU symposium included Zahi Fayad (Mount Sinai), David Saloner (University of California San Francisco), Danny Bluestein (Stony Brook University), Frank Gijsen (Erasmus Medical Center), Rita Z. Goldstein (Icahn School of Medicine at Mount Sinai), Shunichi Kobayashi (Shinshu University), Quan Long (Brunel University, UK), Yubo Fan (Beihang University), Mian Long (Chinese Academy of Sciences), Jiang, Zonglai Jiang (Shanghai Jiaotong University), Ning Gu (Southeast University), Naifeng Liu (Zhongda Hospital, Southeast University), Gaojun Teng (Zhongda Medical School, Southeast University), Zhi-Yong Li (Southeast University), Keqiang Wang (Medical School, Fudan University), Weiyi Chen (Taiyuan University of Science and Technology), Xiaoyan Deng (Beihang University), Fabao Gao (Sichuan university), Xueying Huang (Xiamen University), Liang Li (Sichuan University), Youjun Liu (Beijing University of Technology), Ai'ke Qiao (Beijing University of Technology), Shengzhang Wang (Fudan University), Li Yang (Chongqing University), Yuyu Yao (Zhongda Hospital, Southeast University), Qi Yuan (Xi'an Jiaotong University), Wen Zeng (Sichuan Primed Bio-tech Co., Chengdu, China), Yiyi Zhan (South China University of Technology), Xizheng Zhang (Academy of Military Medical Science), Jian Zhu (Zhongda Hospital, Southeast University), and many others. Abstracts presented at the SEU symposium provided here for easy reference [50-74].

\section{Specific themes of the symposia}

Due to the complexity and multi-disciplinary nature of the problems faced by the researchers, we need to combine medical imaging and modeling with other modalities for better potential in patient screening and clinical event prediction. Computational modeling should be integrated with in vivo intravascular ultrasound (IVUS), angiography, Magnetic Resonance Imaging (MRI), mechanical testing, and histological analysis to analyze vulnerable atherosclerotic plaques and identify critical blood flow and plaque stress/strain indicators which may be used for quantitative carotid/coronary plaque vulnerability assessment. The papers presented with intensive panel discussions at the two symposia were focused on the following four specific themes:

Theme 1. Identify critical issues encountered in medical image acquisition related to cardiovascular diseases and vulnerable plaque research and develop corresponding strategies including image resolution, disease and vulnerable plaque identification, cap thickness, intraplaque hemorrhage, and thrombosis;

Theme 2. Identify critical issues in mechanical testing and quantification of material properties and other boundary conditions such as vessel branching, flow rate and velocity specifications, surface inflammation and blood pressure; 
Theme 3. Identify critical issues in model development, disease and plaque assessment, mechanisms, prediction of rupture and clinical events; discuss issues related to method and model sharing and training of students and junior researchers. Conduct Image-Based FSI Modeling Workshop;

Theme 4. Validate model predictions and assessment plan. Discuss how clinicians can use mechanical and modeling analysis in clinical and surgical applications; Medical device (stent) improvement; Research dissemination and commercialization, transforming research to clinical practices.

\section{Problems and topics discussed}

The invited speakers and participants at the symposia had intensive discussions on the following critical issues and major challenges:

a) Gold standard for in vivo assessment of vulnerable plaques. Histology has been serving as the gold standard for imaging technique development, as well as plaque assessment and classifications. However, such a gold standard does not exist for investigations based on in vivo data. How do we proceed to establish such gold standards and bench marks for plaque assessment?

b) It is known that MRI and IVUS still need to have better resolution to better quantify thin plaque caps, lumen surface conditions, plaque components, and detect vulnerable plaques. What are the possible ways to further develop imaging techniques to meet those needs?

c) How could we use in vivo imaging techniques to determine blood pressure and material properties? What are the barriers and strategies to overcome them?

d) What are the basic skills needed in constructing FSI models based on in vivo data? What are the strategies to reduce the intensive model construction labor? Best practice for sharing?

e) What are the challenges in discovering possible mechanisms governing plaque progression and rupture? How could we validate our findings?

f) How do we identify potential risk factors and quantify their prediction power for clinical events?

g) Strategies to bring research closer to realistic patient screening and diagnostic applications.

\section{Future directions}

Discussion of the topics leads to future tasks and directions. Interdisciplinary collaborations will definitely be needed. Researchers should go beyond their own expertise to understand the bigger picture so that they could further advance their own area.

a) Medical images need to improve resolution so that models can have more accurate data;

b) Image-based models will include more complete in vivo data and make better predictions;

c) Predictive methods should be developed and validated by clinical follow-up studies for potential clinical implementations; 
d) Data and model sharing will help to advance research closer to "precision medicine";

e) Bring research to practice: software development, medical devices, and commercialization.

\section{Papers selected in this issue}

Papers selected in this special issue cover a variety of new areas and topics. New modeling papers including work by Molony et al. showing significant differences for models with and without coronary branches [15], Lu et al. paper for neovessels with intraplaque hemorrhage [16], Sanyal and Han's paper for plaques with buckling [17], Barrett et al.'s paper characterizing human atherosclerotic carotid plaque tissue composition and morphology using combined spectroscopic and imaging modalities [18], and Liu's paper investigating influence of model boundary conditions on blood flow patterns in coronary plaque models [19]. Cunnane et al. used simulation of human atherosclerotic femoral plaque tissue to study the influence of plaque material model on numerical results [20]. Ventricle model papers included a review paper by Lee et al. [21] and a mechanical analysis paper by Gan et al. [22]. Experimental and numerical studies of the circle of Willis were presented by Zhu et al. [23] and Ren et al. [24]. Several papers presented new imaging techniques for better resolutions and/or applications [25-28]. Papers by Chen et al. and Liu et al. represented some effort in medical device and clinical interventions [29,30]. Das' et al. paper represented an effort in automating numerical method for potential software implementation and commercialization [31], even though some simple samples were used for illustration. This is certainly a limited collection of papers from the participants of the symposia. Rather than presenting results and providing solutions, the purpose of the symposia was to identify problems and future directions. Some of those were given in Sections $4 \& 5$. We need all the wisdom we can get collectively from all the disciplines and researchers to overcome the challenges we are facing.

Competing interests

Other than the grants listed in the acknowledgement section, the authors declare that they have no other competing interest.

\section{Authors' contributions}

All authors actively contributed to the research and the writing of the manuscript. DT and ZYL were guest editors for the special issue. DT and ZYL were the organizers for the SEU symposium. DT, FG and DPG were the organizers for the WPI symposium. Professors David N Ku and Danny Bluestein were organizers for the WPI symposium but could not attend due to last-minute schedule conflict. All authors have made substantial contributions and have been involved in drafting the manuscript or revising it critically for important intellectual content; and have given final approval of the version to be published. Each author has participated sufficiently in the work to take public responsibility for appropriate portions of the content.

\section{Acknowledgements \\ The WPI symposium was partially supported by a grant from NIH/NIBIB 1 R13 EB018724.}

\section{Declarations}

Publication of this supplement has not been supported by any sponsorship. Publication of this article was paid with funding from Tang's WPI funds. Information about the source of funding for other articles can be found in the individual articles.

This article has been published as part of BioMedical Engineering OnLine Volume 14 Supplement 1, 2015 :

Cardiovascular Disease and Vulnerable Plaque Biomechanics. The full contents of the supplement are available online at http://www.biomedical-engineering-online.com/supplements/14/S1

\section{Authors' details}

${ }^{1}$ School of Biological Science and Medical Engineering, Southeast University, Nanjing 210096, China. ${ }^{2}$ Department of Mathematical Sciences, Worcester Polytechnic Institute, Worcester, MA 01609, USA. ${ }^{3}$ Department of Biomedical 
Published: 9 January 2015

\section{References}

1. Glagov S, Zarins CK, Giddens DP, Ku DN: Mechanical factors in the pathogenesis, localization and evolution of atherosclerotic plaques. In Diseases of the Arterial wall. Berlin: Springer-Verlag;Camilleri B, Fiessinger B 1989:217-39.

2. Samady H, Eshtehardi P, McDaniel MC, Suo J, Dhawan SS, Maynard C, Timmins LH, Quyyumi AA, Giddens DP: Coronary artery wall shear stress is associated with progression and transformation of atherosclerotic plaque and arterial remodeling in patients with coronary artery disease. Circulation 2011, 124:779-788.

3. Stone PH, Saito S, Takahashi S, Makita Y, Nakamura S, Kawasaki T, Takahashi A, Katsuki T, Nakamura S, Namiki A, Hirohata A, Matsumura T, Yamazaki S, Yokoi H, Tanaka S, Otsuji S, Yoshimachi F, Honye J, Harwood D, Reitman M, Coskun AU, Papafaklis MI, Feldman CL, PREDICTION Investigators: Prediction of progression of coronary artery disease and clinical outcomes using vascular profiling of endothelial shear stress and arterial plaque characteristics: the PREDICTION Study. Circulation 2012, 126(2):172-81.

4. Tang D, Teng Z, Canton G, Yang C, Ferguson M, Huang X, Zheng J, Woodard PK, Yuan C: Sites of rupture in human atherosclerotic carotid plaques are associated with high structural stresses: an in vivo MRI-based 3D fluid-structure interaction study. Stroke 2009, 40(10):3258-3263, Featured article on MDlinx.com. PMID: 19628799. PMCID: PMC2753753.

5. Tang D, Yang C, Mondal S, Liu F, Canton G, Hatsukami TS, Yuan C: A negative correlation between human carotid atherosclerotic plaque progression and plaque wall stress: in vivo mri-based $2 \mathrm{~d} / 3 \mathrm{~d}$ fsi models, Featured article (March 2008) by the Society for Heart Attack Prevention and Eradication. J Biomechanics 2008, 41/4:727-736, PMID: 18191138.

6. Bluestein D, Alemu Y, Avrahami I, Gharib M, Dumont K, Ricotta JJ, Einav S: Influence of microcalcifications on vulnerable plaque mechanics using FSI modeling. J Biomech 2008, 41(5):1111-8.

7. Fayad ZA, Fallon JT, Shinnar M, Wehrli S, Dansky HM, Poon M, Badimon JJ, Charlton SA, Fisher EA, Breslow JL, Fuster V: Noninvasive in vivo high-resolution MRI of atherosclerotic lesions in genetically engineered mice. Circulation 1998, 98:1541-1547.

8. Fuster V: The Vulnerable Atherosclerotic Plaque: Understanding, Identification, and Modification. AHA Monograph series, Futura Publishing, Armonk NY;Valentin Fuster, Co-Editors: J Fredrick Cornhill, Robert E Dinsmore, John T Fallon, William Insull, Peter Libby, Steven Nissen, Michael E Rosenfeld, William D Wagner 1998.

9. Kelly-Arnold A, Maldonado N, Laudier D, Aikawa E, Cardoso L, Weinbaum S: Revised microcalcification hypothesis for fibrous cap rupture in human coronary arteries. Proc Natl Acad Sci USA 2013, 110(26):10741-6.

10. Underhill HR, Hatsukami TS, Fayad ZA, Fuster V, Yuan C: MRI of carotid atherosclerosis: clinical implications and future directions. Nature Reviews Cardiology 2010, 7(3):165-173.

11. Giddens DP, Zarins CK, Glagov S: The role of fluid mechanics in the localization and detection of atherosclerosis. J Biomech Engng 1993, 115: 588-594.

12. Gijsen FJ, Wentzel JJ, Thury A, Lamers B, Schuurbiers JC, Serruys PW, van der Steen AF: A new imaging technique to study 3-D plaque and shear stress distribution in human coronary artery bifurcations in vivo. J Biomech 2007, 40(11):2349-57.

13. Groen HC, Gijsen FJ, van der Lugt A, Ferguson MS, Hatsukami TS, van der Steen AF, Yuan C, Wentzel JJ: Plaque rupture in the carotid artery is localized at the high shear stress region: a case report. Stroke 2007, 38:2379-81.

14. Tang D, Kamm RD, Yang C, Zheng J, Canton G, Bach R, Huang X, Hatsukami TS, Zhu J, Ma G, Maehara A, Mintz GS, Yuan C: Image-based modeling for better understanding and assessment of atherosclerotic plaque progression and vulnerability: Data, modeling, validation, uncertainty and predictions. Journal of Biomechanics 2014, 47:834-846.

15. Molony DS, Timmins LH, Hung OY, Rasoul-Arzrumly E, Samady H, Giddens DP: An assessment of intra-patient variability on observed relationships between wall shear stress and plaque progression in coronary arteries. BioMedical Engineering, OnLine, 1471-2105-X-SZ-S16.

16. Lu J, Duan W, Qiao A: Finite element analysis of mechanics of neovessels with intraplaque hemorrhage in carotid atherosclerosis. BioMedical Engineering, OnLine, 1471-2105-X-SZ-S4.

17. Sanyal A, Han HC: Artery buckling affects the mechanical stress in atherosclerotic plaques. BioMedical Engineering, OnLine, 1471-2105-X-SZ-S17.

18. Barrett HE, Mulvihill JJE, Cunnane EM, Walsh MT: Characterising human atherosclerotic carotid plaque tissue composition and morphology using combined spectroscopic and imaging modalities. BioMedical Engineering, OnLine, 1471-2105-X-SZ-S8.

19. Liu B, Zheng J, Bach R, Tang D: Influence of model boundary conditions on blood flow patterns in a patient specific stenotic right coronary artery. BioMedical Engineering, OnLine, 1471-2105-X-SZ-S10.

20. Cunnane EM, Mulvihill JJE, Barrett HE, Walsh MT: Simulation of human atherosclerotic femoral plaque tissue: the influence of plaque material model on numerical results. BioMedical Engineering, OnLine, 1471-2105-X-SZ-S6.

21. Lee N, Taylor MD, Banerjee RK: Right ventricle-pulmonary circulation dysfunction: a review of energy-based approach. BioMedical Engineering, OnLine, 1471-2105-X-SZ-S15.

22. Gan Y, Chen Q, Zhang S, Ju S, Li ZY: MRI-based strain and strain rate analysis of left ventricle: a modified hierarchical transformation model. BioMedical Engineering, OnLine, 1471-2105-X-SZ-S11.

23. Zhu G, Yuan Q, Yang J, Yeo JH: Experimental study of hemodynamics in the Circle of Willis. BioMedical Engineering, OnLine, 1471-2105-X-SZ-S9.

24. Ren Y, Chen Q, Li ZY: A 3D numerical study of the collateral capacity of the circle of Willis with anatomical variation in the posterior circulation. BioMedical Engineering, OnLine, 1471-2105-X-SZ-S12.

25. Chen C, Wang J, Li K, Liu YP, Chen X: Visual fatigue caused by watching 3DTV: an fMRI study. BioMedical Engineering, OnLine, 1471-2105-X-SZ-S3. 
26. Zeng W, Wen X, Gong L, Sun J, Yang J, Liao J, Qian C, Chen W, Song B, Gao F: Establishment and ultrasound characteristics of atherosclerosis in rhesus monkey. BioMedical Engineering, OnLine, 1471-2105-X-SZ-S7.

27. Hou M, Chen C, Tang D, Luo S, Yang F, Gu N: Magnetic microbubble-mediated ultrasound-MRI registration based on robust optical flow model. BioMedical Engineering, OnLine, 1471-2105-X-SZ-S5.

28. Li G, Luo S, Yan Y, Gu N: A method of extending the depth of focus of the high-resolution X-ray imaging system employing optical lens and scintillator: a phantom study. BioMedical Engineering, OnLine, 1471-2105-X-SZ-S18.

29. Chen Y, Xiong Y, Jiang W, Yan F, Guo M, Wang Q, Fan Y: Numerical simulation on the effects of drug eluting stents at different Reynolds numbers on hemodynamic and drug concentration distribution. BioMedical Engineering, OnLine, 1471-2105-X-SZ-S2.

30. Liu H, Yuan W, Qin KR, Hou J: Acute effect of cycling intervention on carotid arterial hemodynamics: basketball athletes versus sedentary controls. BioMedical Engineering, OnLine, 1471-2105-X-SZ-S1.

31. Das D, Paul A, Taylor M, Banejee RK: Pulsatile arterial wall-blood flow interaction with wall pre-stress computed using an inverse algorithm. BioMedical Engineering, OnLine, 1471-2105-X-SZ-S14.

32. Barrett HE, Mulvihill JJ, Cunnane EM, Walsh MT: Calcific inclusion size and morphology predict plaque rupture behaviour: a microtomographicalanalysis. WPI Symposium, Abstract Book, p.15.

33. Chow MJ, Turcotte R, Lin CP, Zhang K: Arterial extracellular matrix: a mechanobiological study of the contributions and interactions of elastin and collagen. WPI Symposium, Abstract Book, p.16.

34. Cunnane EM, Mulvihill JJ, Barrett HE, Walsh MT: On the mechanical behaviour of superficial femoral artery plaques: the influence of plaque experimental data on numerical results. WPI Symposium, Abstract Book, p.17.

35. Das A, Paul A, Taylor M, Banerjee RK: Pulsatile arterial wall-blood flow interaction with wall pre-stress computed using an inverse algorithm. WPI Symposium, Abstract Book, p.18.

36. Gallo D, Cristofanelli S, Ponzini R, Rizzo G, Steinman DA, Morbiducci U: On the multidirectional nature of disturbed shear and its relationship with helical flow in aorta. WPI Symposium, Abstract Book, p.19.

37. Gijsen F: MRI-based carotid plaque biomechanics: can we measure plaque geometry accurate enough? WPI Symposium, Abstract Book, p.20

38. Gillard JH: Multi-modality/multi-discipline approach for cardiovascular research: issues, challenges, and opportunities. WPI Symposium, Abstract Book, p.21

39. Kobayashi $\mathrm{S}$, Miyamoto D: Flow and deformation in arterial stenosis model for percutaneous transluminal coronary angioplasty. WPI Symposium, Abstract Book, p.23.

40. Lee N, Banerjee RK, Hor KN, Taylor MD: Non-invasive assessment on pulmonary insufficiency: energy-based approach using 4D phase contrast MRI. WPI Symposium, Abstract Book, p.24.

41. Maldonado N, Cardoso L, Weinbaum S: Biomechanics of vulnerable plaque rupture: role of cap microcalcifications. WPI Symposium, Abstract Book, p.25.

42. Molony D, Timmins L, Rasoul-Arzrumly E, Hung O, Samady H, Giddens DP: Assessment of intrasubject variability and relationships between plaque progression and wall shear stress in human coronary arteries. WPI Symposium, Abstract Book, p.26.

43. Molony D, Timmins L, Rasoul-Arzrumly E, Hung O, Samady H, Giddens DP: Does coronary side-branch exclusion alter wall shear stress predictions of plaque progression? WPI Symposium, Abstract Book, p.27.

44. Pei X, Li ZY: Effect of calcification on plaque vulnerability: insights from a fatigue analysis. WPI Symposium, Abstract Book, p.29.

45. Saloner D: MR imaging in the evaluation of the contributions of morphology, inflammation, and hemodynamics in vascular disease. WPI Symposium, Abstract Book, p.30.

46. Sanyal A, Han HC: Mechanical buckling and tortuosity of arteries affects the wall stress in atherosclerotic plaque. WPI Symposium, Abstract Book, p.31.

47. Stone PH: In-vivo risk stratification of individual coronary artery plaques: an evolving paradigm for preemptive management of patients with CAD. WPI Symposium, Abstract Book, p.32.

48. Tang D, Kamm RD, Yang C, Wang L, Zheng J, Canton G, Bach R, Billiar KL, Huang X, Maehara A, Mintz GS, Yuan C: Image-based modeling for vulnerable plaque assessment and prediction: What can image-based modeling contribute? WPI Symposium, Abstract Book, p.33.

49. Teng Z, Brown AJ, Sadat U, Bennett MR, Gillard JH: The incremental benefit to plaque vulnerability assessment using mechanical analysis. WPI Symposium, Abstract Book, p.34.

50. Bluestein D: Optimizing the performance and thromboresistance of mechanical circulatory support and cardiovascular devices. SEU Symposium, Program Book, p.22.

51. Deng $X$ : Studies on the correlation between the accelerated atherogenesis of the venous graft and its water filtration rate. SEU Symposium, Program Book, p.23.

52. Fan Y: Mechanobiological study on the vascular cells under the physiological pulsatile flow. SEU Symposium, Program Book, p.24.

53. Fayad ZA: Precision diagnostic, big data and nanomedicine in cardiovascular disease detection and treatment. SEU Symposium, Program Book, p.25.

54. Fayad ZA: Inflammation \& multimodality imaging in cardiovascular disease. SEU Symposium, Program Book, p.25,

55. Zeng W, Wen X, Gong L, Sun J, Yang J, Liao J, Xia R, Qian C, Chen W, Song B, Gao F: Establishment and dynamic image study of an atherosclerosis plaque rhesus monkey model. SEU Symposium, Program Book, p.26.

56. Gijsen F, Wentzel J, van der Steen A: Image-based mechanical analyses of carotid plaques. SEU Symposium, Program Book, p.27.

57. Goldstein RZ: The neurobiology underlying drug addiction: lessons from multimodality imaging and neuropsychological studies in humans. SEU Symposium, Program Book, p.28.

58. Huang $X$ : Quantifying effect of intraplaque hemorrhage on critical plaque wall stress in human atherosclerotic plaques: 3D MRI-based FSI study. SEU Symposium, Program Book, p.29.

59. Kobayashi S, Miyamoto D: Flow and deformation in coronary stenosis model for percutaneous transluminal coronary angioplasty. SEU Symposium, Program Book, p.30

60. Kuang W, Tang M, He X, Wu W, Liu X, Li L: Differentiation of rat bone marrow-derived mesenchymal stem cells into cardiomyocyte-like cells induced by cyclic mechanical strain. SEU Symposium, Program Book, p.31. 
61. Pei X, Li ZY: A fatigue model for plaque rupture: A comparison between symptomatic and asymptomatic patients. SEU Symposium, Program Book, p.32.

62. Liu NF: Fluorine-18 labeled Ne-carboxymethyl-lysine as molecular imaging probe for metabolic pathway of advanced glycation end products in vivo. SEU Symposium, Program Book, p.33.

63. Li J, Zhao M, Lu L, Wu W, Li L, Liu X: Cardiomyocyte differentiation of amniotic epithelial cells: synergism of biochemical and biomechanical stimuli. SEU Symposium, Program Book, p.34.

64. Liu Y: Hemodynamics simulation of coronary artery bypass grafting with different surgical procedures: a numerical study using OD/3D coupling method. SEU Symposium, Program Book, p.35.

65. Liu Y, Fu Y, Qiao AK: The influence of hemodynamics on the ulceration plaques of carotid artery stenosis. SEU Symposium, Program Book, p.36.

66. Gong Y, Zhang Y, Liu X, Lü S, Long M: Dynamic contribution of P-selectin, E-selectin and intercellular adhesion molecule-1 in neutrophil transmigration. SEU Symposium, Program Book, p.37.

67. Long Q: Computational modelling of emboli travel trajectories in cerebral arteries. SEU Symposium, Program Book, p.38.

68. Qiao AK, Lu J, Liu Y: Numerical analysis of the effect on plaque hemorrhage by the neovessels in carotid atherosclerotic plaque. SEU Symposium, Program Book, p.39.

69. Saloner D: The determination of morphologic and physiologic features for assessing the impact of hemodynamics on vascular disease. SEU Symposium, Program Book, p.40.

70. Tang D: Image-based modeling for vulnerable plaque assessment and prediction: what we know, what we do not know, and what we really want to know. SEU Symposium, Program Book, p.41.

71. Yao Y, Cheng K, Cheng Z, Zhang Y, Li Y, Sheng Z, Wen S, Ma GS, Liu NF, Fang F, Teng GJ: In vivo imaging of macrophages and MMP activity of abdominal aortic aneurysm using high resolution MRI in ApoE-/- mice. SEU Symposium, Program Book, p.42-43.

72. Zhu G, Yuan Q, Yeo JH: Experimental study of hemodynamics in the circle of willis. SEU Symposium, Program Book, p.44.

73. Zhan Y, Chen X, Fang Y, WU J: Biomechanical modeling and analysis of local disturbed flow through stenosis. SEU Symposium, Program Book, p.45.

74. Zhu J, Fekete N, Bornstedt A, Ma G, Merkle N, Liu N, Rottbauer W, Rasche V: Cardiac MR imaging in the rat model on a clinical 3Tesla whole-body system. SEU Symposium, Program Book, p.46.

doi:10.1186/1475-925X-14-S1-S1

Cite this article as: Tang et al:: Cardiovascular diseases and vulnerable plaques: data, modeling, predictions and clinical applications. BioMedical Engineering OnLine 2015 14(Suppl 1):S1.

\section{Submit your next manuscript to BioMed Central and take full advantage of:}

- Convenient online submission

- Thorough peer review

- No space constraints or color figure charges

- Immediate publication on acceptance

- Inclusion in PubMed, CAS, Scopus and Google Scholar

- Research which is freely available for redistribution 